\title{
On Volatility Transmission from Crude Oil to Agricultural Commodities
}

\author{
Dilip Kumar \\ Indian Institute of Management, Kashipur, India \\ Email: dilip.kumar@iimkashipur.ac.in
}

How to cite this paper: Kumar, D. (2017) On Volatility Transmission from Crude Oil to Agricultural Commodities. Theoretical Economics Letters, 7, 87-101. https://doi.org/10.4236/tel.2017.72009

Received: November 14, 2016

Accepted: January 31, 2017

Published: February 3, 2017

Copyright (C) 2017 by author and Scientific Research Publishing Inc. This work is licensed under the Creative Commons Attribution International License (CC BY 4.0).

http://creativecommons.org/licenses/by/4.0/

\begin{abstract}
The paper examines volatility transmission from crude oil market to agricultural commodities like wheat, corn, cotton and soybeans. We find that the volatility transmission from crude oil to agricultural commodities exhibits sudden changes over a study period. We also examine whether the sudden changes in volatility influence the observed sudden changes in volatility transmission from crude oil to agricultural commodities. Our results indicate the observed sudden change in volatility transmission mechanism is not influenced by sudden changes in volatility series.
\end{abstract}

\section{Keywords}

Volatility Spillover, Crude Oil, Agricultural Commodities,

Volatility Estimator, Sudden Changes

\section{Introduction}

Crude oil prices have shown wider fluctuations and have experienced higher volatility in last many decades. Crude oil plays important role in industrial production, transportation, and many other sectors and indirectly influences the economy as well. The inflation-adjusted crude oil prices exhibit sudden change during 2005 due to Iraq war. The behaviour of crude oil prices experiences sudden change soon after 2005. In 2006, events like Iraq war, Israel war, Lebanon war and other geographical tensions pushed up the crude price to $\$ 75$ per barrel. In 2007, the ongoing problems in Turkey, subprime crisis in the US took up the price to $\$ 92.22$ per barrel. The crude oil prices reached its peak of $\$ 147.02$ per barrel in mid of 2008. However, in next few months, crude oil prices exhibited heavier decline and price dropped to around $\$ 100$ per barrel by the end of December 2008. During 2010, crude oil prices exhibit fluctuations between $\$ 70$ and $\$ 88$ per barrel. The political and macroeconomic events linked to oil producing 
countries like Libya, Yemen, Egypt and Bahrain again pushed the oil prices above $\$ 100$ in 2011 and 2012. From 2013 onwards, high production of shale by the US, low demand of the oil in China and Europe and uninterrupted production of the oil by OPEC members put the oil price on the downturn and in 2015 it was fluctuating around $\$ 60$ per barrel.

Crude oil is considered to be the most important commodity in term of its daily traded value and consumption and is known to be the life-blood of the given economy. Hence, it is important to examine the characteristics of crude oil price changes. Crude oil is part of the production function of many commodities including agricultural commodities. In one way or the other, crude oil prices also influence the price changes in agricultural commodities (Mitchell [1]). Moreover, commodities like soybeans, sugar and corn can be used for the production of bio-ethanol and bio-diesel which can act as a substitute for crude oil, hence, the crude oil prices can be considered to be linked with agricultural commodities prices (Chang and $\mathrm{Su}[2]$ ). The production of these bio-fuels depends on the supply of raw materials (corn, soybeans) which affect the sensitivity of price changes of these commodities with respect to price changes in crude oil (Schmidhuber [3]). Commodities like natural rubber and manmade fibres have an alternative in the form of synthetic rubber which is one of the by-products of crude oil.

The prices of many important agricultural commodities have shown an upward trend during the period 2006 to mid of 2008. In the mid of 2008 when the crude oil prices were at the peak, the prices of major agricultural commodities were also at the record high level. This also highlights the presence of inter-linkages between crude oil prices and agricultural commodities prices. Moreover, the fluctuating agricultural commodities prices will always remain a cause of concern to regulators, government, consumers, and traders.

The fluctuating crude oil prices significantly influence the economy of both oil exporting and oil importing countries by impacting different sectors of the economy. The growth in commodity markets around the globe has also provided immense opportunities to global investors, speculators and traders. Now, investors and other market participants have started using commodities in their portfolios for hedging and risk management (Baffes and Hanitis [4]). Such use of commodities as an asset in portfolio significantly influences the integration relationship between agricultural commodities and crude oil (Nazlioglu et al. [5]).

The core objective of this study is to examine the behaviour of volatility spillover between agricultural commodities (wheat, corn, cotton and soybeans) and crude oil. We estimate the dynamic volatility spillover coefficients to highlight the evolutionary characteristics of the volatility spillover and to examine the impact of market crashes and crises on sudden changes in this evolutionary behaviour of volatility spillover. The sudden changes in volatility spillover effect may be related to the presence of contagion from crude oil to agricultural commodities. In this paper, we also test whether the sudden changes in volatility spillover from crude oil to agricultural commodities is actually contagion or not. 
The rest of the paper is structured as follow: Section 2 presents a literature review. Section 3 provides data description, research methodology used in the paper and some preliminary analysis of data. Sections 4 and 5 present empirical results and final conclusions, respectively.

\section{Literature Review}

Various studies have been conducted to analyze the co-movements in agricultural commodities prices and crude oil prices. Using monthly data of Crude oil, copper, gold, wheat, cotton, cocoa, lumber and cocoa, Pindyck and Rotemberg [6] find strong correlation between crude oil and other agricultural commodities and highlight that the correlation is mainly influenced by herding in these commodity markets. Palakas and Varangis [7] also make use of monthly data of crude oil, silver, wheat, coffee, cotton, lead, copper and rubber to examine cointegration relationship among them and find strong evidence of co-movement in these commodities. Baffes [8] used annual data to analyze the impact of crude oil price on 35 internationally traded commodities for a period of 45 years ranging from 1960 to 2005 and find that crude oil prices have long run impact on prices of agricultural commodities. Campiche et al. [9] used weekly data for a period from 2003 to 2007 to examine cointegration relationship among Crude oil prices and corn, sorghum, sugar, soybeans, soybean oil, and palm oil and find no long run relationship between crude oil and agricultural commodities prices. Using monthly data of Crude oil, corn, soy meal, and pork, Zhang and Reed [10] highlighted that crude oil prices show weak relationship with the agricultural commodities. Harri, Nalley and Hudson [11] and Chang and Su [2] examine the volatility spillover from crude oil futures to corn futures and find that volatility spillover from crude oil to corn are mainly significant during the periods of crisis and crashes in markets. Alghalith [12] and Chen et al. [13] also find significant impact of return volatility in crude oil prices on return volatility of agricultural commodities. Gohin and Chantret [14] find a negative relationship between crude oil prices and agricultural commodity markets. However, Gilbert and Morgan [15] obtained opposite findings as crude oil prices negatively impact the agricultural commodity prices. Using co-integration approach, Saghaian [16] and Alom et al. [17] observed strong correlation between crude oil prices and agricultural commodities prices. However, Mutuc et al. [18] and Zhang et al. [19] find no direct correlation between crude oil prices and agricultural commodities prices. Moreover, Kaltalioglu and Soutas [20] did not find any evidence of volatility spillover from crude oil to agricultural commodities. Cha and Bae [21] and Du et al. [22] find significant evidence of volatility spillover from crude oil to agricultural commodities. Serra [23] finds significant evidence of volatility spillover between crude oil, bioethanol and sugar prices in Brazilian market. Nazlioglu and Soytas [24] examine the dynamic relationship of 24 agricultural commodities prices with crude oil prices using panel data analysis and find strong positive impact of fluctuations in crude oil prices on prices of agricultural commodities. On the other hand, Reboredo [25] finds weak impact of crude oil 
prices on agricultural commodities prices. Using multivariate GARCH approach, Gardebroek and Hernandez [26] examine the volatility spillover from crude oil market to agricultural commodity market but find no significant evidence of volatility spillover.

However, $\mathrm{Wu}$ and $\mathrm{Li}$ [27] find significant volatility spillover from crude oil to corn and ethanol market. Mensi et al. [28] examine the dynamic linkages between energy market and agricultural commodities (mainly grains) and find evidence of significant linkages between these markets. Wang et al. [29] examine the influence of crude oil price shocks on agricultural commodities before and after crisis of 2007-08 and find that the impact of crude oil prices on agricultural commodities prices are higher during the post-crisis period. Jiang, Marshand Tozer [30] examine the volatility transmission from crude oil to corn and find that this market interlink ages depend on ethanol-gasoline consumption ratio. Fernandez-Perez, Frijns and Tourani-Rad [31] examine the contemporaneous interactions among energy (oil and ethanol) and agricultural commodities (corn, soybean, and wheat) in the United States using structural VAR model which incorporate the impact of heteroskedasticity and find evidence of unidirectional contemporaneous impact from crude oil to the agricultural commodities.

Most of the previous studies examine the volatility and information spillover from crude oil to agricultural commodities. Under the influence of various crashes and crises, this interrelationship may not remain structurally stable and most of the earlier studies fail to highlight this. In this study, we highlight that the time varying volatility spillover from crude oil to agricultural commodities does not remain statistically constant but exhibit occasional sudden changes which highlights the evidence of contagion.

\section{Data and Methodology}

\subsection{Data}

We use open, high, low and close prices data to estimate unbiased Rogers and Satchell [32] range based volatility estimator. Data of near month futures of wheat, corn, cotton, soybeans and crude oil have been taken for a period from Jan 2006 to April 2015. We use West Texas Intermediate (WTI) crude oil futures traded on the New York Mercantile Exchange (NYMEX). All data have been obtained from the Bloomberg database. Bloomberg is the highly renowned and trusted database for the area of economics and finance and is accepted worldwide for fetching real time data.

\subsection{Rogers and Satchell (1991) Range Based Volatility Estimator}

Rogers and Satchell [32] derive an extreme value estimator for the unconditional variance of an asset price which has the attractive property that it remains unbiased for any value of the drift. Suppose $O_{t} H_{t} L_{t}$ and $C_{t}$ are the opening, high, low and closing prices of an asset on day $t$. Define:

$$
b_{t}=\log \left(\frac{H_{t}}{O_{t}}\right)
$$




$$
\begin{gathered}
c_{t}=\log \left(\frac{L_{t}}{O_{t}}\right) \\
x_{t}=\log \left(\frac{C_{t}}{O_{t}}\right) .
\end{gathered}
$$

Suppose $\operatorname{var} x$ denotes the usual estimator of $\sigma^{2}$, i.e.

$$
\operatorname{var} x=\frac{1}{N-1} \sum_{n=1}^{N}\left(x_{n}-\hat{\mu}\right)^{2}
$$

where

$$
\hat{\mu}=\frac{1}{N} \sum_{n=1}^{N} X_{n} .
$$

Let $u_{t}=2 b_{t}-x_{t}$ and $v_{t}=2 c_{t}-x_{t}$, define the extreme value estimator var $u x$ and $\operatorname{var} v x$ :

$$
\begin{gathered}
\operatorname{var} u x=\frac{1}{N} \sum_{n=1}^{N}\left(\frac{u_{n}^{2}-x_{n}^{2}}{2}\right) \\
\operatorname{var} v x=\frac{1}{N} \sum_{n=1}^{N}\left(\frac{v_{n}^{2}-x_{n}^{2}}{2}\right) .
\end{gathered}
$$

Hence the unbiased extreme value estimator of variance as proposed by Rogers and Satchell [32] is given by:

$$
\operatorname{var} u x v x=\operatorname{avg}\{\operatorname{var} u x, \operatorname{var} v x\}=\frac{\operatorname{var} u x+\operatorname{var} v x}{2} .
$$

In this paper, we propose the use of var $u x v x$ in place of $\varepsilon_{t}^{2}$ to detect structural breaks in the variance of the time series.

\subsection{Inclan and Tiao's (IT) [33] ICSS Algorithm}

We apply Inclan and Tiao [33] approach to detect sudden changes in volatility estimator. Suppose $\varepsilon_{t}$ is a time series with zero mean and with unconditional variance $\sigma^{2}$. Suppose the variance within each interval is given by $\tau_{j}^{2}$, where $j=0,1, \cdots, N_{T}$ and $N_{T}$ is the total number of variance changes in $T$ observations, and $1<k_{1}<k_{2}<\cdots<k_{N T}<T$ are the change points.

$$
\begin{gathered}
\sigma_{t}^{2}=\tau_{0}^{2} \text { for } 1<t<\kappa_{1} \\
\sigma_{t}^{2}=\tau_{1}^{2} \text { for } \quad \kappa_{1}<t<\kappa_{2} \\
\sigma_{t}^{2}=\tau_{N T}^{2} \text { for } \quad \kappa_{N T}<t<T .
\end{gathered}
$$

In order to estimate the number of changes in variance and the time point of each variance shift, a cumulative sum of squares procedure is used. The cumulative sum of the squared observations from the start of the series to the $k^{\text {th }}$ point in time is given as:

$$
C_{k}=\sum_{t=1}^{k} \varepsilon_{t}^{2}
$$

where $k=1, \cdots, T$. The $D_{k}(\mathrm{IT})$ statistics is given as: 


$$
D_{k}=\left(\frac{C_{k}}{C_{T}}\right)-\frac{k}{T}, k=1, \cdots, T \text { with } D_{0}=D_{T}=0
$$

where $C_{T}$ is the sum of squared residuals from the whole sample period.

If there are no sudden changes in the variance of the series then the $D_{k}$ statistic oscillates around zero and when plotted against $k$, it looks like a horizontal line. On the other hand, if there are sudden changes in the variance of the series, then the $D_{k}$ statistics values drift either above or below zero.

\subsection{Heterogeneous Autoregressive (HAR) Model}

The HAR model proposed by Corsi [34] uses the principle of Heterogeneous Market Hypothesis to approximately capture the heterogeneity in the market which can be due to different kind of market participants with short (daily), medium (weekly) and long-term (monthly) investment horizons. The HAR model for the $R S$ estimator is given as:

$$
\log (R S)_{t}^{(d)}=\alpha_{0}+\alpha_{d} \log (R S)_{t-1}^{(d)}+\alpha_{w} \log (R S)_{t-1}^{(w)}+\alpha_{m} \log (R S)_{t-1}^{(m)}+\varepsilon_{t}
$$

where $\log \left(X_{-} R S\right)_{t-1}^{(d)}$ is the lagged daily $\log (R S)$ estimator of the given agricultural commodity, $\log \left(X_{-} R S\right)_{t-1}^{(w)}=\frac{1}{5} \sum_{i=1}^{5} \log \left(X_{-} R S\right)_{t-i}^{(d)}$ is the lagged weekly volatility component and $\log \left(X_{-} R S\right)_{t-1}^{(m)}=\frac{1}{22} \sum_{i=1}^{22} \log \left(X_{-} R S\right)_{t-i}^{(d)}$ is the lagged monthly volatility component. We include lagged volatility component of WTI in the above model to examine the spillover effect.

$$
\begin{aligned}
\log \left(X_{-} R S\right)_{t}^{(d)}= & \alpha_{0}+\alpha_{d} \log \left(X_{-} R S\right)_{t-1}^{(d)}+\alpha_{w} \log \left(X_{-} R S\right)_{t-1}^{(w)} \\
& +\alpha_{m} \log \left(X_{-} R S\right)_{t-1}^{(m)}+\beta_{d} \log \left(W T I_{-} R S\right)_{t-1}^{(d)}+\varepsilon_{t}
\end{aligned}
$$

We have used MATLAB software to perform the analysis.

\subsection{Descriptive Statistics}

Table 1 presents the summary statistics of $\log (R S)$ of the data considered in this study. On average, wheat appears to be highly volatile than other commodities and volatility in soybeans prices is the least. The volatility of volatility (the standard deviation of $\log (R S)$ estimator) is the highest for cotton, however, the volatility of volatility is quite comparable across all the given commodities. The volatility of wheat and cotton are negatively skewed and all commodities volatilities exhibit significant excess kurtosis. Significant values of Jarque-Bera statistic indicate that the $\log (R S)$ of the given commodities do not follow the normal distribution exactly. However, the smaller values of skewness and kurtosis highlight that the distribution of $\log (R S)$ can be approximately Gaussian. We highlight this by plotting histogram in Figure 1. The significant values of the Ljung Box statistic $(Q(20))$ indicate significant autocorrelation in $\log (R S)$ series up to 20 lags. Significant ARCH(10) statistic indicate the presence of ARCH effect in $\log (R S)$ series of the given commodities.

Table 2 presents the correlation matrix for the given $\log (R S)$ series. Wheat, 
Table 1. Descriptive statistics.

\begin{tabular}{cccccc}
\hline & Wheat & Corn & Cotton & Soybeans & WTI \\
\hline Mean & 1.072 & 0.868 & 0.518 & 0.414 & 0.994 \\
Median & 1.090 & 0.815 & 0.559 & 0.336 & 0.943 \\
Min & -4.470 & -1.951 & -7.056 & -2.470 & -3.888 \\
Max & 5.764 & 4.959 & 4.044 & 4.029 & 5.189 \\
Stdev & 1.010 & 0.986 & 1.297 & 0.966 & 1.041 \\
Skewness & -0.143 & 0.238 & -0.544 & 0.380 & 0.345 \\
Kurtosis & 4.341 & 2.896 & 4.493 & 3.240 & 3.650 \\
JB test & $184.230^{\#}$ & $23.199^{\#}$ & $334.394^{\#}$ & $62.194^{\#}$ & $88.028^{\#}$ \\
& $(0.000)$ & $(0.000)$ & $(0.000)$ & $(0.000)$ & $(0.000)$ \\
Q(20) & $4428.369^{*}$ & $4432.020^{\#}$ & $3608.105^{\#}$ & $4474.883^{\#}$ & $15369.452^{\#}$ \\
& $(0.000)$ & $(0.000)$ & $(0.000)$ & $(0.000)$ & $(0.000)$ \\
& $525.701^{\#}$ & $448.847^{\#}$ & $323.893^{\#}$ & $519.909^{\#}$ & $1252.773^{\#}$ \\
ARCH(10) & $(0.000)$ & $(0.000)$ & $(0.000)$ & $(0.000)$ & $(0.000)$ \\
\hline
\end{tabular}

${ }^{*}$ represents significant at $1 \%$ level of significance. The terms in parenthesis represent $p$-values.
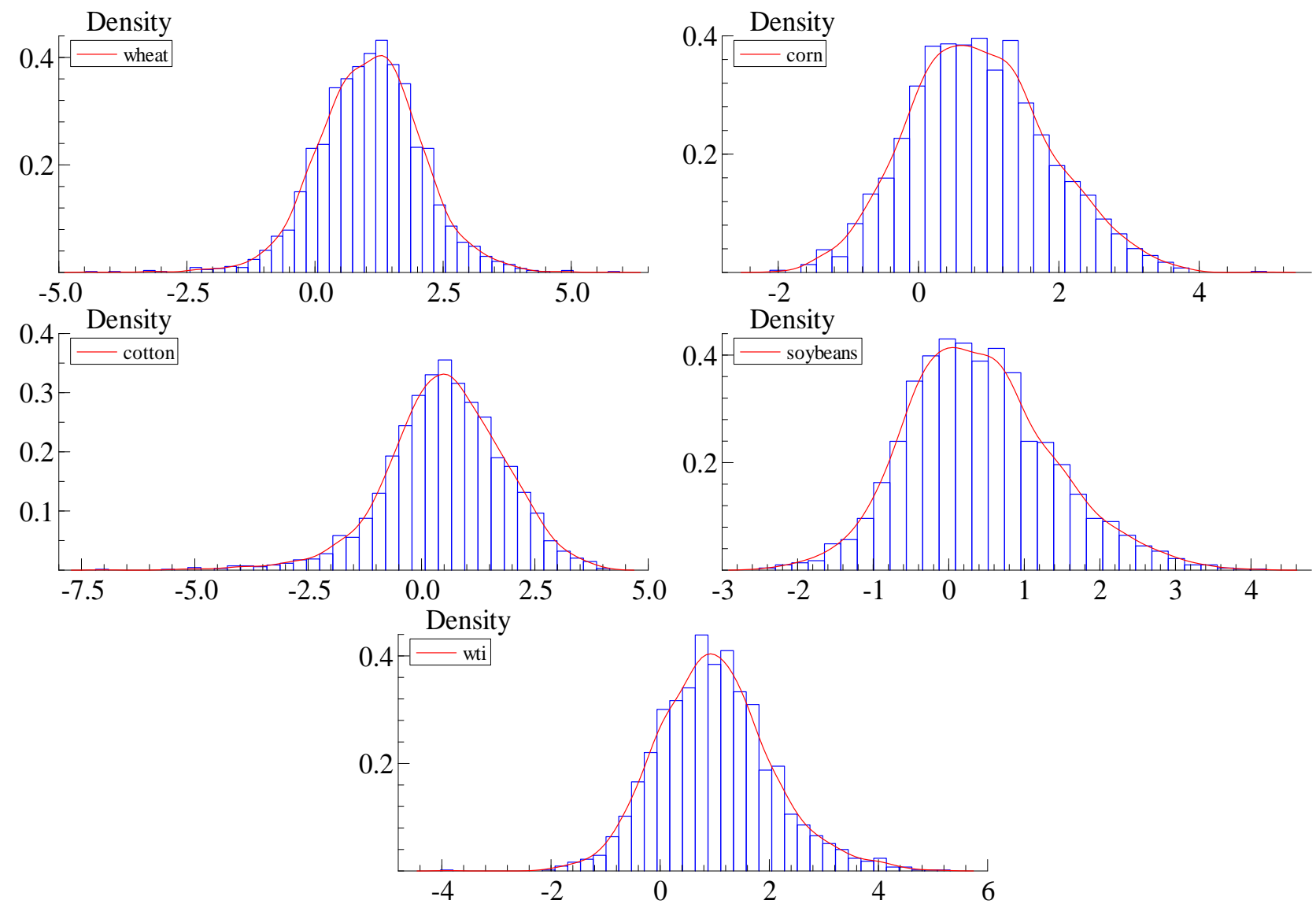

Figure 1. Histogram with kernel density of $\log (R S)$. 
Table 2. Correlation matrix.

\begin{tabular}{cccccc}
\hline & Wheat & Corn & Cotton & Soybeans & WTI \\
\hline Wheat & 1.000 & 0.522 & 0.254 & 0.413 & 0.336 \\
Corn & 0.522 & 1.000 & 0.247 & 0.532 & 0.339 \\
Cotton & 0.254 & 0.247 & 1.000 & 0.232 & 0.220 \\
Soybeans & 0.413 & 0.532 & 0.232 & 1.000 & 0.307 \\
WTI & 0.336 & 0.339 & 0.220 & 0.307 & 1.000 \\
\hline
\end{tabular}

corn and soybeans show nearly similar correlation with crude oil (greater than $30 \%)$. However, cotton, on average, exhibits $22 \%$ correlation with respect to crude oil.

Figure 1 shows the histogram of $\log (R S)$ of the given commodities with kernel density. The distribution of $\log (R S)$ series appear to be nearly Gaussian.

\section{Empirical Results}

First we examine the volatility spillover effect from crude oil to agricultural commodities based on full sample analysis. Next, we perform moving sub-sample analysis to examine the evolution of volatility spillover from crude oil to agricultural commodities and look forward to see the reason of observed breaks in volatility spillover mechanism from crude oil to agricultural commodities.

\subsection{HAR model Estimation}

Table 3 presents the parameter estimates of the given HAR framework for the full sample. The lagged daily, weekly and monthly volatility components of all the commodities are positive and significant at $1 \%$ level of significance.

Results indicate that the monthly and weekly volatility components have major impact on current volatility of the given commodities in comparison to lagged daily volatility component. The lagged daily volatility component of crude oil is positive and significant at conventional levels of significance for all the given commodities. However, the influence of crude oil volatility component is the highest for corn followed by wheat, cotton and soybeans. This may be related to relationship between crude oil and bio-fuels produced from corn. The adjusted $R^{2}$ is the highest for wheat followed by corn, soybeans and cotton. Overall, our findings indicate that the HAR model appropriately captures the volatility spillover effect from crude oil to the given agricultural commodities for whole sample. Next, we will analyze the structural stability of the volatility spillover using time varying volatility spillover analysis. If we observe any structural breaks in volatility transmission mechanism, then we will look forward to examine if these structural breaks in volatility spillover represent contagion or these are due to increase in volatility during crashes and crisis, that is, heteroskedasticity. 
Table 3. Parameter estimates of HAR model.

\begin{tabular}{ccccc}
\hline & Wheat & Corn & Cotton & Soybeans \\
\hline$\alpha_{0}$ & $0.158^{\#}$ & $0.108^{\#}$ & $0.077^{*}$ & 0.031 \\
$\alpha_{d}$ & $(0.035)$ & $(0.031)$ & $(0.033)$ & $(0.024)$ \\
& $0.084^{\#}$ & $0.147^{\#}$ & $0.173^{\#}$ & $0.081^{*}$ \\
$\alpha_{W}$ & $(0.025)$ & $(0.025)$ & $(0.026)$ & $(0.025)$ \\
& $0.265^{\#}$ & $0.119^{*}$ & $0.193^{\#}$ & $0.206^{\#}$ \\
$\alpha_{m}$ & $(0.049)$ & $(0.047)$ & $(0.047)$ & $(0.049)$ \\
& $0.450^{\#}$ & $0.528^{\#}$ & $0.450^{\#}$ & $0.534^{*}$ \\
$\beta_{d}$ & $(0.051)$ & $(0.050)$ & $(0.049)$ & $(0.052)$ \\
& $0.059^{\#}$ & $0.070^{*}$ & $0.047^{*}$ & $0.043^{*}$ \\
Adj $R^{2}$ & $(0.019)$ & $(0.019)$ & $(0.023)$ & $(0.018)$ \\
F-stat & 0.294 & 0.293 & 0.268 & 0.286 \\
\hline
\end{tabular}

${ }^{*}$ and ${ }^{*}$ mean significant at $1 \%$ and $5 \%$ levels of significance.

\subsection{Volatility Spillover from Crude Oil to Agricultural Commodities over Time}

We make use of moving window (of 250 observations) to re-estimate the HAR model so as to extract the spillover parameter estimates from crude oil to agricultural commodities. These time-varying spillover coefficients are plotted with $95 \%$ confidence band. We make use of robust stand errors to generate $95 \%$ confidence band. Figure 2 reports the plots for time varying volatility spillover effect from crude oil to the given agricultural commodities with 95\% confidence band.

The solid line represents the volatility spillover parameter estimates and corresponding dashed lines represent the $95 \%$ confidence band. The straight lines represent whole spillover parameter estimate with $95 \%$ confidence band. Results clearly indicate that the time varying volatility spillover effect from crude oil to agricultural commodities do not remain stable and exhibit wider variations over the given time period. We observe significant jumps in volatility spillover mechanism during the period 2010-2011 for wheat; during 2008, 2010 and 2014 for corn; during 2007-08 and 2014 for cotton; and during 2008 and 2013-14 for soybeans. The structural breaks in volatility spillover mechanism are observed during the periods when time varying volatility spillover confidence band violates the whole sample volatility spillover confidence band. The periods of 2007-08 can be related to the period of global financial crisis. The period of 2010-2014 can be related to European debt crisis and wars in various Middle East countries. Overall, our findings indicate the presence of structural breaks in volatility spillover from crude oil to the agricultural commodities during various turbulent periods. These structural breaks in volatility spillover parameters can be related to the presence of contagion. 

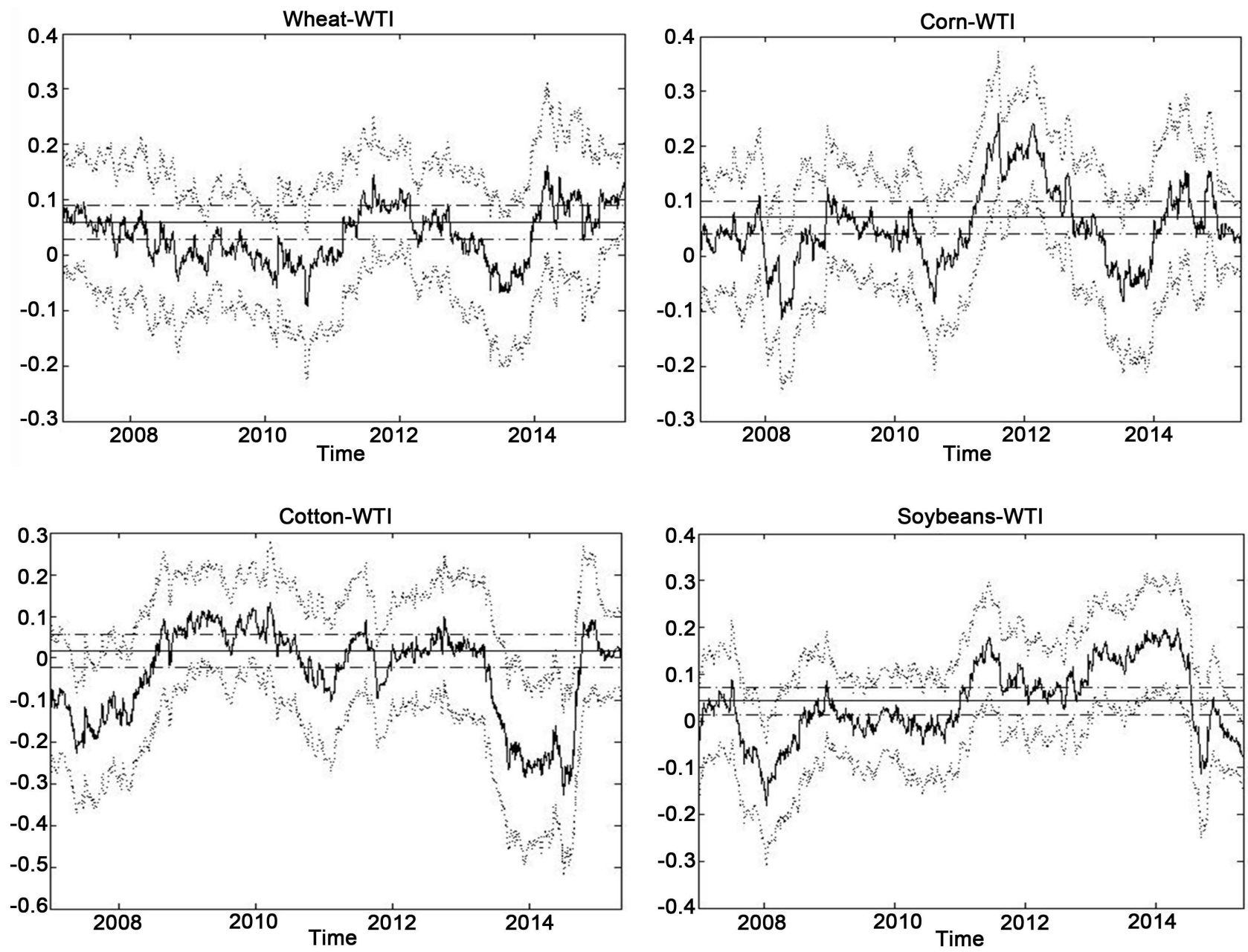

Figure 2. Time varying volatility spillover.

\subsection{Do Sudden Changes in Volatility Impact the Sudden Changes in Volatility Spillover?}

Next, we test whether the presence of structural breaks in volatility explains the structural breaks observed in volatility spillover from crude oil to agricultural commodities. We apply Inclan and Tiao's [33] test to detect structural break dates in $\log (R S)$ estimator. Figure 3 presents the $\log (R S)$ of all commodities with volatility regimes. We obtain two volatility regimes in nearly all the given commodities.

Next, we incorporate the impact of these structural breaks in volatility and generate break adjusted $\log (R S)$ estimator. Next, we apply HAR framework using moving windows to examine the impact of structural breaks in volatility on observed structural breaks in volatility spillover. Figure 4 presents the plots of time varying volatility spillover from crude oil to agricultural commodities based on the break adjusted $\log (R S)$. Results indicate that the evolution of volatility spillover from crude oil to agricultural commodities for the break adjusted data exhibit similar pattern and characteristics as shown by $\log (R S)$. This indicates that the structural breaks in volatility series do not explain the structural breaks in volatility spillover pattern from crude oil to agricultural commodities. This 

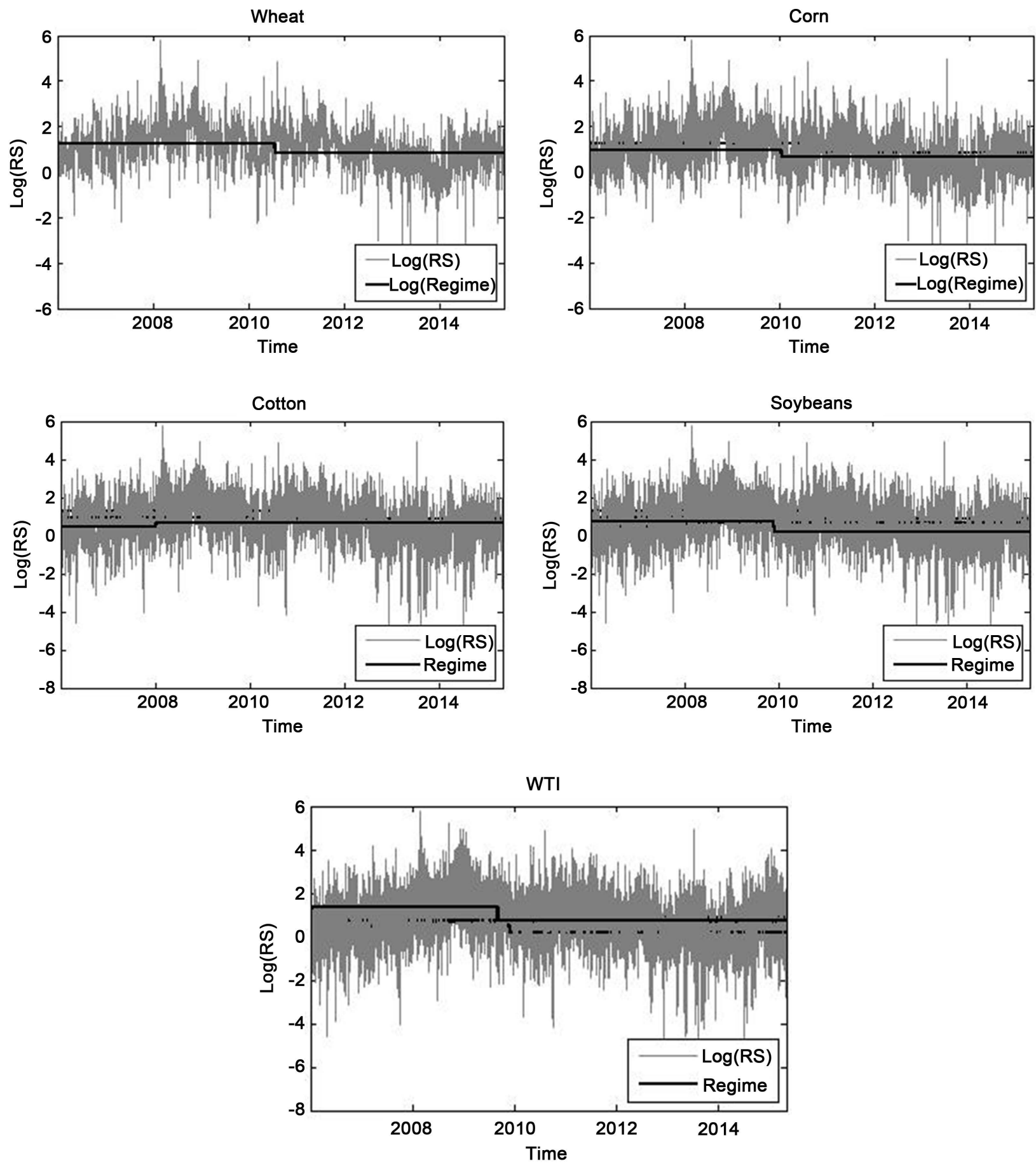

Figure 3. $\log (R S)$ with volatility regimes.

supports the evidence of contagion from crude oil to the given agricultural commodities during the period of crashes and crisis in markets.

\subsection{Policy Implications}

Volatility spillover from crude oil to agricultural commodities has several policy implications from the perspective of policy makers, government, investors, portfolio managers and risk managers. From the perspective of policy makers and 

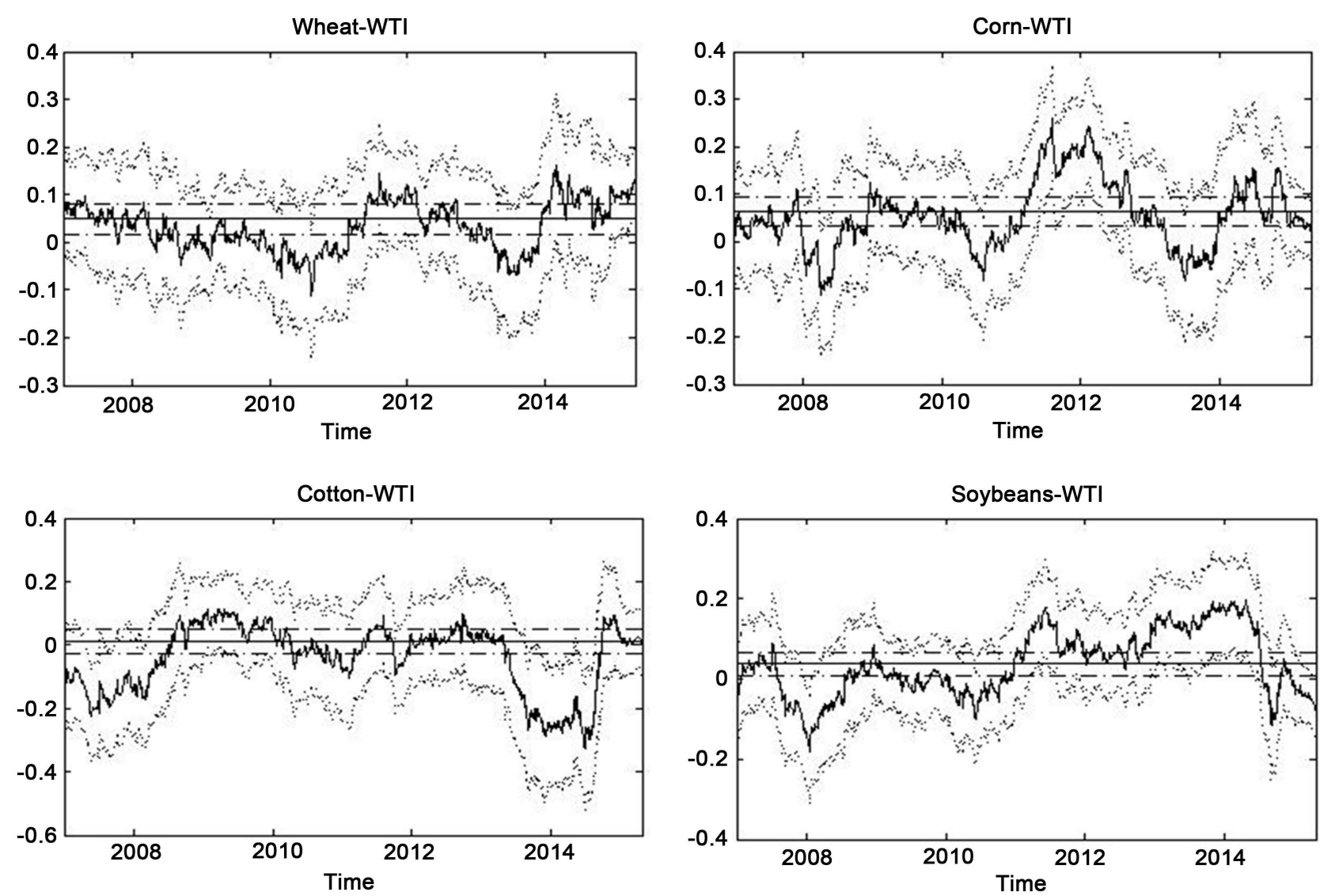

Figure 4. Time varying volatility spillover for $\log (R S)$ adjusted for breaks.

government, predicting sudden changes in volatility spillover from crude oil prices to agricultural commodities can help in designing and implementing the subsidy measures for a particular commodity. During the periods of turbulence in crude oil prices, the structure of volatility spillover deviates from its common behaviour. This can be helpful to avoid impact of increase in commodities prices on general public of the country. The findings of the study also have implications towards portfolio management by optimally including crude oil and agricultural commodities in portfolio to get benefit of diversification. The findings of the study also have implications towards risk management in the sense of generating more accurate measure of market risk, that is, Value-at-Risk or expected shortfall measures.

\section{Conclusion}

The main objective of this paper is to examine what impacts the observed structural breaks in volatility spillover mechanism from crude oil to agricultural commodities. Using daily data, we first examine the impact of volatility in crude oil on volatility of agricultural commodities (wheat, corn, cotton and soybeans) based on heterogeneous autoregressive (HAR) model for whole sample. We find evidence of significant volatility spillover from crude oil to agricultural commodities based on whole sample analysis. The period of study is influenced by various 
periods of turbulence and evolution of volatility spillover from crude to agricultural commodities may not remain stable. Next, we estimate time varying volatility spillover parameters from crude oil to agricultural commodities and find that indeed the volatility spillover from crude oil to agricultural commodities does not remain stable but exhibit multiple structural breaks which can be related to the evidence of contagion from crude oil to agricultural commodities. Next, we test whether the structural breaks in volatility can explain the observed structural breaks in measuring volatility spillover mechanism. Our findings indicate that the structural breaks in volatility do not explain observed structural breaks in volatility spillover which support the evidence of significant contagion from crude oil to agricultural commodities during the periods of crashes and crisis. Further research can be conducted to understand the reasons of structural breaks in volatility spillover from crude oil agricultural commodities.

\section{References}

[1] Mitchell, D. (2008) A Note on Rising Food Prices. Policy Research Working Paper No. 4682, World Bank, Washington, DC.

[2] Chang, T.H. and Su, H.M. (2010) The Substitutive Effect of Biofuels on Fossil Fuels in the Lower and Higher Crude Oil Price Periods. Energy Economics, 35, 28072813. https://doi.org/10.1016/j.energy.2010.03.006

[3] Schmidhuber, J. (2007) Biofuels: An Emerging Threat to Europe's Food Security? http://www.institutdelors.eu/media/policypaper-schmidhuber-en.pdf?pdf=ok

[4] Baffes, J. and Haniotis, T. (2010) Placing the 2006-08 Commodity Price Boom into Perspective. Policy Research, Working Paper, World Bank.

[5] Nazlioglu, S., Erdem, C. and Soytas, U. (2013) Volatility Spillover between Oil and Agricultural Commodity Markets. Energy Economics, 36, 658-665. https://doi.org/10.1016/j.eneco.2012.11.009

[6] Pindyck, R.S. and Rotemberg, J.J. (1990) The Excess Co-Movement of Commodity Prices. Economics Journal, 100, 1173-1189. https://doi.org/10.2307/2233966

[7] Palaskas, T.B. and Varangis, P.N. (1991) Is There Excess Co-Movement of Primary Commodity Prices? A Cointergration Test. Working Paper Series No. 758, International Economic Department, World Bank, Washington.

[8] Baffes, J. (2007) Oil Spills on Other Commodities. Resource Policy, 32, 126-134. https://doi.org/10.1016/j.resourpol.2007.08.004

[9] Campiche, J.L., Bryant, H.L., Richardson, J.W. and Outlaw, J.L. (2007) Examining the Evolving Correspondence between Petroleum Prices and Agricultural Commodity Prices. The American Agricultural Economics Association Annual Meeting, Portland, OR, 29 July-1 August 2007, 1-15.

[10] Zhang, Q. and Reed, M. (2008) Examining the Impact of the World Crude Oil Price on China's Agricultural Commodity Prices: The Case of Corn, Soybean, and Pork. The Southern Agricultural Economics Association Annual Meetings, Dallas, TX, 2-5 February 2008, 1-17.

[11] Harri, A., Nalley, L. and Hudson, D. (2009) The Relationship between Oil, Exchange Rates, and Commodity Prices. Journal of Agricultural and Applied Economics, 41, 501-510. https://doi.org/10.1017/S1074070800002959

[12] Alghalith, M. (2010) The Interaction between Food Prices and Oil Prices. Energy Economics, 32, 1520-1522. https://doi.org/10.1016/j.eneco.2010.08.012 
[13] Chen, S.-T., Kuo, H.I. and Chen, C.C. (2010) Modelling the Relationship between the Oil Price and Global Food Prices. Applied Energy, 87, 2517-2525. https://doi.org/10.1016/j.apenergy.2010.02.020

[14] Gohin, A. and Chantret, F. (2010) The Long-Run Impact of Energy Prices on World Agricultural Markets: The Role of Macro-Economic Linkages. Energy Policy, 38, 333-339. https://doi.org/10.1016/j.enpol.2009.09.023

[15] Gilbert, C.L. and Morgan C.W. (2010) Food Price Volatility. In: Piot-Lepetit, I. and M'Barek, R., Eds., Methods to Analyse Agricultural Commodity Price Volatility, Springer, New York, 45-61. http://link.springer.com/chapter/10.1007\%2F978-1-4419-7634-5_4

[16] Saghaian, S.H. (2010) The Impact of the Oil Sector on Commodity Prices: Correlation or Causation? Journal of Agricultural and Applied Economics, 42, 477-485. https://doi.org/10.1017/S1074070800003667

[17] Alom, F., Ward, B. and Baiding, H. (2011) Spillover Effects of World Oil Prices on Food Prices: Evidence from Asia and Pacific Countries. 52nd New Zealand Association of Economists Annual Conference, Wellington, 29 June-1 July 2011, 1-28.

[18] Mutuc, M., Pan, S. and Hudson, D. (2010) Response of Cotton to Oil Price Shocks. The Southern Agricultural Economics Association Annual Meeting, Orland, 6-9 February 2010, 1-15.

[19] Zhang, Z., Lohr, L., Escalante, C. and Wetzstein, M. (2010) Food versus Fuel: What Do Prices Tell Us? Energy Policy, 38, 445-451. https://doi.org/10.1016/j.enpol.2009.09.034

[20] Kaltalioglu, M. and Soytas, U. (2009) Price Transmission between World Food, Agricultural Raw Material, and Oil Prices. GBATA International Conference Proceedings, Prague, 7-11 July 2009, 596-603.

[21] Cha, K.S. and Bae, J.H. (2011) Dynamic Impacts of High Oil Prices on the Bioethanol and Feed-Stock Markets. Energy Policy, 39, 753-760.

https://doi.org/10.1016/j.enpol.2010.10.049

[22] Du, X., Yu, C.L. and Hayes, D.J. (2011) Speculation and Volatility Spillover in the Crude Oil and Agricultural Commodity Markets: A Bayesian Analysis. Energy Economics, 33, 497-503. https://doi.org/10.1016/j.eneco.2010.12.015

[23] Serra, T. (2011) Volatility Spillovers between Food and Energy Markets: A Semiparametric Approach. Energy Economics, 33, 1155-1164.

https://doi.org/10.1016/j.eneco.2011.04.003

[24] Nazlioglu, S. and Soytas, U. (2012) Oil Price, agricultural Commodity Prices, and the Dollar: A Panel Cointegration and Causality Analysis. Energy Economics, 34, 1098-1104. https://doi.org/10.1016/j.eneco.2011.09.008

[25] Reboredo, J.C. (2012) Do Food and Oil Prices Co-Move? Energy Policy, 49, 456467. https://doi.org/10.1016/j.enpol.2012.06.035

[26] Gardebroek, C. and Hernandez, M.A. (2012) Do Energy Prices Stimulate Food Price Volatility? Examining Volatility Transmission between US Oil, Ethanol and Corn Markets.

http://ageconsearch.umn.edu/bitstream/124583/2/draft_energy_corn_CG_MH_jun e_1_2012_AAEA.pdf

[27] Wu, H, and Li, S. (2013) Volatility Spillovers in China's Crude Oil, Corn and Fuel Ethanol Markets. Energy Policy, 62, 878-886. https://doi.org/10.1016/j.enpol.2013.07.026

[28] Mensi, W., Hammoudeh, S. and Yoon, S-M. (2014) Structural Breaks and Long Memory in Modelling and Forecasting Volatility of Foreign Exchange Markets of 
Oil Exporters: The Importance of Scheduled and Unscheduled New Announcements. International Review of Economics and Finance, 30, 101-119. https://doi.org/10.1016/j.iref.2013.10.004

[29] Wang, Y., Wu, C. and Yang, L. (2014) Oil Price Shocks and Agricultural Commodity Prices. Energy Economics, 44, 22-35. https://doi.org/10.1016/j.eneco.2014.03.016

[30] Jiang, J., Marsh, T.L. and Tozer, P.R. (2015) Policy Induced Price Volatility Transmission: Linking the US Crude Oil, Corn and Plastics Markets. Energy Economics, 52, 217-227. https://doi.org/10.1016/j.eneco.2015.10.008

[31] Fernandez-Perez, A., Frijns, B. and Tourani-Rad, A. (2016) Contemporaneous Interactions among Fuel, Biofuel and Agricultural Commodities. Energy Economics, 58, 1-10. https://doi.org/10.1016/j.eneco.2016.05.014

[32] Rogers, L.C.G. and Satchell, S.E. (1991) Estimating Variance from High, Low and Closing Prices. The Annals of Applied Probability, 1, 504-512. https://doi.org/10.1214/aoap/1177005835

[33] Inclán, C. and Tiao, G.C. (1994) Use of Cumulative Sums of Squares for Retrospective Detection of Changes of Variance. Journal of the American Statistical Association, 89, 913-923.

[34] Corsi, F. (2009) A Simple Approximate Long-Memory Model of Realized Volatility. Journal of Financial Econometrics, 7, 174-196. https://doi.org/10.1093/jifinec/nbp001

Submit or recommend next manuscript to SCIRP and we will provide best service for you:

Accepting pre-submission inquiries through Email, Facebook, LinkedIn, Twitter, etc. A wide selection of journals (inclusive of 9 subjects, more than 200 journals) Providing 24-hour high-quality service User-friendly online submission system Fair and swift peer-review system Efficient typesetting and proofreading procedure Display of the result of downloads and visits, as well as the number of cited articles Maximum dissemination of your research work

Submit your manuscript at: http://papersubmission.scirp.org/

Or contact tel@scirp.org 